\title{
РЕЗУЛЬТАТИ ДОСЛІДЖЕННЯ ПОКАЗНИКІВ ГЕМОДИНАМІКИ В ЯКОСТІ МАРКЕРІВ ВКЛЮЧЕННЯ ДО ГРУП РИЗИКУ РОЗВИТКУ УСКЛАДНЕНЬ У XВОРИХ 3 ГІПЕРТЕНЗІЄЮ: АНАЛІЗ НА ОСНОВІ RОС-КРИВОЇ
}

\author{
П. Р. Сельський
}

\author{
ДВНЗ "Тернопільський державний медичний університет імені І.Я.Горбачевського"
}

В роботі запропоновано методику оптимізації прогнозувння розвитку захворювань на первиному рівні надання медичної допомоги. В якості маркерів включення до груп ризику погіршення стану та розвитку ускладнень у хворих з гіпертензією досліджено показники гемодинаміки при первинному та повторному обстеженнях. Підхід ґрунтується на аналізі ROC-кривих.

Ключові слова: первинний рівень, гіпертензія, прогнозування захворювання, ROC-криві.

\section{РЕЗУЛЬТАТЫ ИССЛЕДОВАНИЯ ПОКАЗАТЕЛЕЙ ГЕМОДИНАМИКИ В КАЧЕСТВЕ МАРКЕРОВ ВКЛЮЧЕНИЯ В ГРУППЫ РИСКА РАЗВИТИЯ ОСЛОЖНЕНИЙ У БОЛЬНЫХ С ГИПЕРТЕНЗИЕЙ: АНАЛИЗ НА ОСНОВЕ ROC- КРИВОЙ}

\author{
П. Р. Сельський \\ ГВУЗ "Тернопольский государственный медицинский университет \\ имени И. Я. Горбачевского"
}

\begin{abstract}
В работе предложена методика оптимизации прогнозирования развития заболеваний на первичном уровне оказания медицинской помощи. В качестве маркеров включения в группы риска ухудшения состояния и развития осложнений у больных с артериальной гипертензией исследованы показатели гемодинамики при первичном и повторном обследованиях. Подход основан на анализе ROC-кривых.
\end{abstract}

Ключевые слова: первичный уровень, гипертензия, прогнозирование заболевания, ROC-кривые.

\section{RESULTS OF THE HEMODYNAMIC INDICES INVESTIGATION AS TOKEN INCLUSION TO VULNERABLE GROUPS OF DEVELOPING THE PROGRESSION IN PATIENTS WITH HYPERTENSION: ANALYSIS BASED ON THE ROC-CURVE}

\author{
SHEI "Ternopil State Medical University by I.Ya. Horbachevsky"
}

\begin{abstract}
The paper suggests an optimization method for the developing disease prognosis at the primary health care level.
The hemodynamic indices in primary and re-examination as token inclusion to vulnerable groups of health deterioration and developing the progression in patients with hypertension have been investigated. An approach is based on the analysis of ROC-curves.
\end{abstract}

Key words: the primary health care level, hypertension, the disease prognosis, ROC-curves.

Вступ. Ефективна інформатизація роботи сільських лікувальних закладів дає можливість суттєво підвищити якість надання медичних послуг [1]. Численні дослідження спрямовані на вирішення технологічних проблем впровадження новітніх технологій [2, 3, 4], проте не до кінця вирішеною залишається проблема їх використання у сільській медицині та відповідної

(с) П. Р. Сельський підготовки висококваліфікованих спеціалістів. При цьому важливою є оптимізація прогнозування захворювань на первинному рівні з метою корекції обстеження та лікування із застосуванням недорогих та простих у використанні інформаційних методик.

Метою роботи $є$ запропонувати методику оптимізації прогнозування перебігу захворювання у хво- 
рих з гіпертензією за допомогою ROC-аналізу результатів дослідження показників гемодинаміки при первинному та повторному обстеженнях.

Матеріали і методи. В якості даних для аналізу використано результати остеження 63 пацієнтів 3 гіпертензією у навчально-практичних центрах первинної медико-санітарної допомоги (НПЦПМСД), відкритих у селах Гнилиці та Зарубинці Тернопільської області [3], внесених у базу програми "Реєстратура" протягом 20II та $20 \mathrm{I} 2$ років. У 30 (79,37\%) хворих спостерігали стабільний перебіг хвороби, а у I3 (20,б3 \%) виявили погіршення стану та розвиток ускладнень. Здійснювали дослідження показників пульсу та артеріального тиску за результатами першого (первинного, до призначеного лікування) та другого (повторного, в процесі лікування) обстежень хворих. Статистичну обробку матеріалу проводили 3 використанням пакета програм "Microsoft ExсєI" (Microsoft Office 2003).

3 метою оптимізації прогнозування перебігу захворювання у хворих з гіпертензією використано аналіз за допомогою ROC-кривих. Дана методика була вперше використана в теорії обробки сигналів у США під час Другої світової війни для підвищення якості розпізнавання об'єктів супротивника за радіолокаційним сигналом [б]. Згодом широке застосування ROC-криві отримали і в медичній діагностиці. Ця крива відома також як крива помилок. Аналіз класифікацій із застосуванням ROC-кривих називається ROC-аналізом. ROC-крива (англ. receiver operating characteristic, операційна характеристика приймача) - графік, що дозволяє оцінити якість бінарної класифікації та відображає співвідношення між часткою вірних позитивних класифікацій від загального числа позитивних класи- фікацій (англ. true positive rate - TPR) $з$ часткою помилкових позитивних класифікацій від загального числа негативних класифікацій (англ. false positive rate - FPR) при варіюванні порогу вирішального правила. При цьомy TPR називають чутливістю (sensitivity) алгоритму класифікації, а FPR визначають, як 1 -специфічність (1specificity). Відповідно, специфічністю (specificity) алгоритму класифікації називають частку вірних негативних класифікацій (true negative rate - TNR) від загального числа негативних класифікацій. Інтерпретацію ROC дає показник AUC (англ. area under ROC curve, площа під ROC-кривою) - площа, обмежена ROCкривою і віссю частки помилкових позитивних класифікацій. По суті, даний показник є мірою якості класифікатора [7,8].

Результати й обговорення. Визначено 10 рівнів пульсу, від 55 до 100 ударів / хв (з кроком у 5 ударів / хв) за результатами першого та другого обстежень хворих з артеріальною гіпертензією. На кожному рівні (табл. 1 ) визначали TPR (чутливість) показників пульсу за формулою: $\mathrm{TPR}=\mathrm{TP} / \mathrm{TP}+\mathrm{FN}$, де $\mathrm{TP}$ (true positive) - кількість хворих із стабільним перебігом захворювання, показник пульсу у яких дорівнював чи перевищував відповідний рівень, FN (false negative) - кількість хворих із стабільним перебігом захворювання, показник пульсу у яких був нижчим відповідного рівня. TNR (специфічність) показників пульсу визначали за формулою: TNR $=\mathrm{TN} / \mathrm{TN}+\mathrm{FP}$, де XN (true negative) - кількість хворих із погіршенням стану та розвитком ускладнень, показник пульсу у яких дорівнював чи перевищував відповідний рівень, FP (false positive) - кількість хворих із стабільним перебігом захворювання, показник пульсу у яких був нижчим відповідного рівня.

Таблиця 1. Порівняльний аналіз чутливості і специфічності показників пульсу при першому та другому обстеженнях в якості маркерів включення до групи ризику погіршення стану та розвитку ускладнень у пацієнтів з гіпертензією

\begin{tabular}{|c|c|c|c|c|c|c|c|c|c|c|}
\hline \multicolumn{3}{|c|}{$\begin{array}{c}\text { Показники пульсу } \\
(\mathrm{n}=63)\end{array}$} & \multirow{2}{*}{\multicolumn{2}{|c|}{$\begin{array}{c}\text { Кількість хворих } \\
\text { із стабільним } \\
\text { перебігом } \\
(\mathrm{n}=50)\end{array}$}} & \multirow{2}{*}{\multicolumn{2}{|c|}{$\begin{array}{c}\text { Кількість хворих із } \\
\text { погіршенням стану } \\
\text { та розвитком } \\
\text { ускладнень } \\
(\mathrm{n}=13) \\
\end{array}$}} & \multirow{2}{*}{\multicolumn{2}{|c|}{ Чутливість }} & \multirow{2}{*}{\multicolumn{2}{|c|}{ Специфічність }} \\
\hline \multirow{2}{*}{$\begin{array}{c}\text { рівень } \\
\text { пульсу } \\
\text { (кількість } \\
\text { уд./хв) }\end{array}$} & \multicolumn{2}{|c|}{ кількість хворих } & & & & & & & & \\
\hline & $\begin{array}{c}1 \text { обсте- } \\
\text { ження }\end{array}$ & $\begin{array}{c}2 \text { обсте- } \\
\text { ження }\end{array}$ & $\begin{array}{c}1 \text { обсте- } \\
\text { ження }\end{array}$ & $\begin{array}{l}2 \text { обсте- } \\
\text { ження }\end{array}$ & $\begin{array}{c}\text { обсте- } \\
\text { ження }\end{array}$ & $\begin{array}{l}2 \text { обсте- } \\
\text { ження }\end{array}$ & \begin{tabular}{|c|}
1 обсте- \\
ження
\end{tabular} & \begin{tabular}{|c|}
2 обсте- \\
ження
\end{tabular} & $\begin{array}{c}1 \text { обсте- } \\
\text { ження }\end{array}$ & $\begin{array}{c}2 \text { обсте- } \\
\text { ження }\end{array}$ \\
\hline 1 & 2 & 3 & 4 & 5 & 6 & 7 & 8 & \begin{tabular}{|l|}
9 \\
\end{tabular} & 10 & 11 \\
\hline$\geq 55(+)$ & 63 & 63 & 50 & 50 & 13 & 13 & 1,00 & 1,00 & 0,00 & 0,00 \\
\hline$<55(-)$ & 0 & 0 & 0 & 0 & 0 & 0 & & & & \\
\hline$\geq 60$ & 58 & 62 & 45 & 49 & 13 & 13 & 0,90 & 0,98 & 0,00 & 0,00 \\
\hline$<60$ & 5 & 1 & 5 & 1 & 0 & 0 & & & & \\
\hline$\geq 65$ & 57 & 59 & 44 & 47 & 13 & 12 & 0,88 & 0,94 & 0,00 & 0,08 \\
\hline$<65$ & 6 & 4 & 6 & 3 & 0 & 1 & & & & \\
\hline
\end{tabular}


Продовження табл. 1

\begin{tabular}{|c|c|c|c|c|c|c|c|c|c|c|}
\hline 1 & 2 & 3 & 4 & 5 & 6 & 7 & 8 & 9 & 10 & 11 \\
\hline$\geq 70$ & 55 & 54 & 42 & 42 & 13 & 12 & \multirow[t]{2}{*}{0,84} & \multirow[t]{2}{*}{0,84} & \multirow[t]{2}{*}{0,00} & \multirow[t]{2}{*}{0,08} \\
\hline$<70$ & 8 & 9 & 8 & 8 & 0 & 1 & & & & \\
\hline$\geq 75$ & 50 & 43 & 38 & 33 & 12 & 10 & \multirow[t]{2}{*}{0,76} & \multirow[t]{2}{*}{0,66} & \multirow[t]{2}{*}{0,08} & \multirow[t]{2}{*}{0,23} \\
\hline$<75$ & 13 & 20 & 12 & 17 & 1 & 3 & & & & \\
\hline$\geq 80$ & 28 & 34 & 20 & 27 & 8 & 7 & \multirow[t]{2}{*}{0,40} & \multirow[t]{2}{*}{0,54} & \multirow[t]{2}{*}{0,38} & \multirow[t]{2}{*}{0,46} \\
\hline$<80$ & 35 & 29 & 30 & 33 & 5 & 6 & & & & \\
\hline$\geq 85$ & 13 & 18 & 8 & 15 & 5 & 3 & \multirow[t]{2}{*}{0,16} & \multirow[t]{2}{*}{0,30} & \multirow[t]{2}{*}{0,62} & \multirow[t]{2}{*}{0,77} \\
\hline$<85$ & 50 & 45 & 42 & 35 & 8 & 10 & & & & \\
\hline$\geq 90$ & 6 & 6 & 4 & 6 & 2 & 0 & \multirow[t]{2}{*}{0,08} & \multirow[t]{2}{*}{0,12} & \multirow[t]{2}{*}{0,85} & \multirow[t]{2}{*}{1,00} \\
\hline$<90$ & 57 & 57 & 46 & 44 & 11 & 13 & & & & \\
\hline$\geq 95$ & 2 & 1 & 2 & 1 & 0 & 0 & \multirow[t]{2}{*}{0,04} & \multirow[t]{2}{*}{0,02} & \multirow[t]{2}{*}{1,00} & \multirow[t]{2}{*}{1,00} \\
\hline$<95$ & 61 & 62 & 48 & 49 & 13 & 13 & & & & \\
\hline$\geq 100$ & 1 & 0 & 1 & 0 & 0 & 0 & \multirow[t]{2}{*}{0,02} & \multirow[t]{2}{*}{0,00} & \multirow[t]{2}{*}{1,00} & \multirow[t]{2}{*}{1,00} \\
\hline$<100$ & 62 & 63 & 49 & 50 & 13 & 13 & & & & \\
\hline
\end{tabular}

Порівняльний аналіз виявив переважання показників чутливості за результатами визначення показників пульсу при другому обстеженні, порівняно з першим, як маркерів включення до груп ризику розвитку ускладнень пацієнтів з гіпертензією на переважній більшості рівнів. Лише на 2 та 12 рівнях показники чутливості при першому обстеженні переважали. Виявлялось і переважання показників специфічності за результатами другого обстеження, порівняно 3 першим, на переважній більшості рівнів. На двох перших та двох останніх рівнях дані показники не відрізнялись.

3 метою набору масивів даних для побудови ROCкривих проводили визначення показників TPR (чутливість) та FPR (1 -специфічність) за результатами першого та другого обстежень на кожному рівні (табл. 2).

Таблиця 2. Показники TPR (чутливості) та FPR (1-специфічності) за рівнями пульсу при першому та другому обстеженнях хворих з гіпертензією

\begin{tabular}{|c|c|c|c|c|c|}
\multirow{2}{*}{ № за/п } & \multirow{2}{*}{$\begin{array}{c}\text { Рівень пульсу } \\
\text { (кількість уд./хв) }\end{array}$} & \multicolumn{2}{|c|}{ 1 обстеження } & \multicolumn{2}{|c|}{ 2 обстеження } \\
\cline { 3 - 6 } & чутливість & 1-специфічність & чутливість & 1-специфічність \\
\hline 1 & 55 & 1,0 & 1,0 & 1,00 & 1,0 \\
\hline 2 & 60 & 0,90 & 1,0 & 0,98 & 1,0 \\
\hline 3 & 65 & 0,88 & 1,0 & 0,94 & 0,92 \\
\hline 4 & 70 & 0,84 & 1,0 & 0,84 & 0,92 \\
\hline 5 & 75 & 0,76 & 0,92 & 0,66 & 0,77 \\
\hline 6 & 80 & 0,40 & 0,62 & 0,54 & 0,54 \\
\hline 7 & 85 & 0,16 & 0,38 & 0,30 & 0,23 \\
\hline 8 & 90 & 0,08 & 0,15 & 0,12 & 0 \\
\hline 9 & 95 & 0,04 & 0 & 0,02 & 0 \\
\hline 10 & 100 & 0,02 & 0 & 0 & 0 \\
\hline
\end{tabular}

ЯОС-аналіз результатів дослідження показників пульсу при першому та другому обстеженнях хворих з гіпертензією в якості маркерів включення до груп ризику погіршення стану та розвитку ускладнень (рис. 1) показав більшу специфічність та чутливість показників при обстеженні в процесі лікування. Площа, обмежена ЯОС-кривою і віссю частки помилкових позитивних класифікацій більша при даному обстеженні, порівняно з першим, що показує на вищу якість даного класифікатора.

Визначено 13 рівнів верхнього (систолічного) артеріального тиску від 110 мм рт. ст. до 230 мм рт. ст. (3 кроком у 10 мм рт. ст) за результатами першого та другого обстежень пацієнтів з гіпертензією. На кожномy рівні (табл. 3) визначали TPR (чутливість) показників артеріального тиску за формулою: TPR=TP / TP + FN, де TP (true positive) - кількість хворих із стабільним перебігом захворювання, показник артеріального тиску у яких дорівнював чи перевищував відповідний рівень, FN (false negative) - кількість хворих із стабільним перебігом захворювання, показник артеріального тиску у яких був нижчим відповідного рівня. TNR (специфічність) показників артеріального тиску визначали за формулою: TNR=TN / TN+FP, де TN (true negative) 
- кількість хворих із погіршенням стану та розвитком ускладнень, показник артеріального тиску у яких дорівнював чи перевищував відповідний рівень, FP (false positive) - кількість хворих із стабільним перебігом захворювання, показник артеріального тиску у яких був нижчим відповідного рівня.

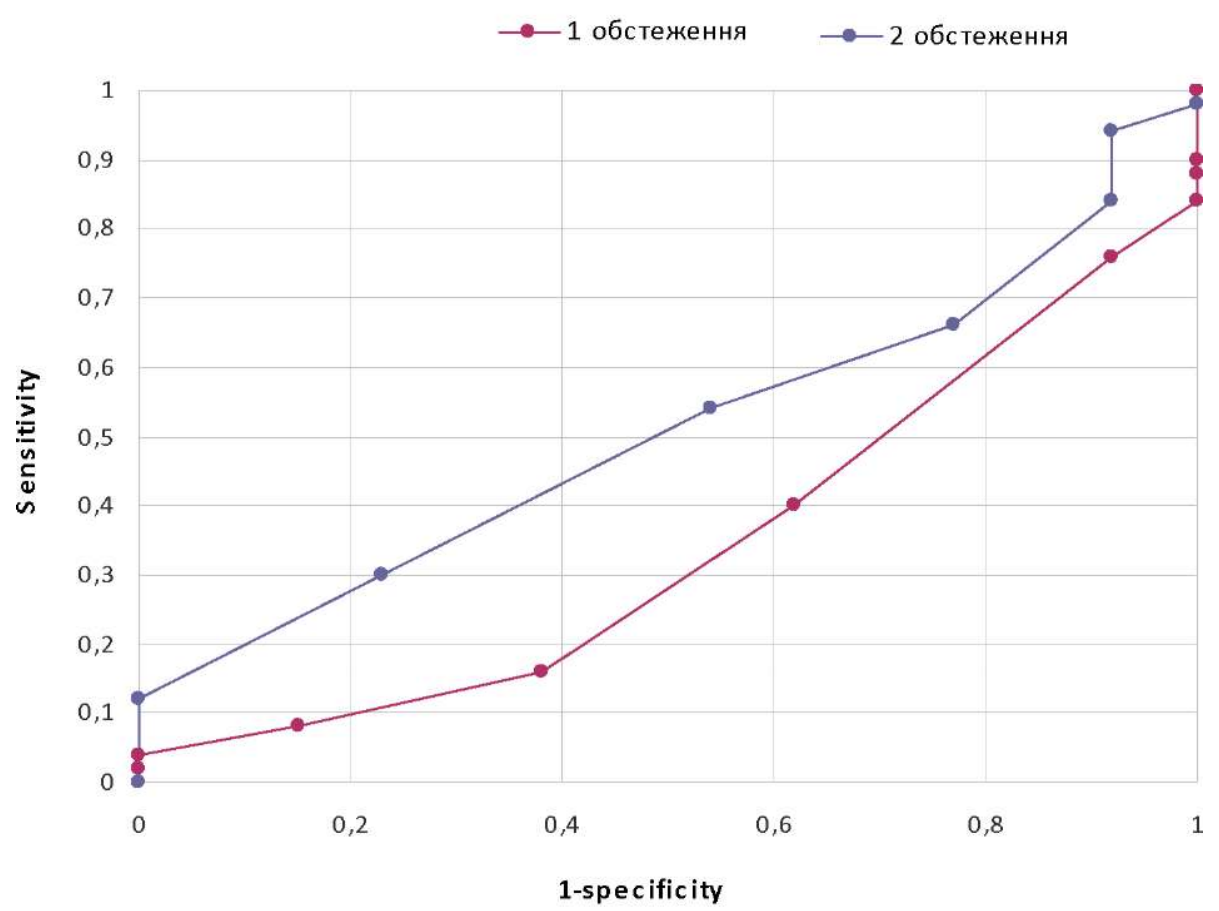

Puc. 1. ЯОС-аналіз результатів дослідження показників пульсу при першому та другому обстеженнях в якості маркерів включення до групи ризику погіршення стану та розвитку ускладнень у пацієнтів 3 гіпертензією.

Таблиця 3. Порівняльний аналіз чутливості і специфічності показників верхнього артеріального тиску при першому та другому обстеженнях в якості маркерів включення до групи ризику погіршення стану та розвитку ускладнень у пацієнтів 3 гіпертензією

\begin{tabular}{|c|c|c|c|c|c|c|c|c|c|c|}
\hline \multicolumn{3}{|c|}{$\begin{array}{c}\text { Показники пульсу } \\
(\mathrm{n}=63)\end{array}$} & \multirow{2}{*}{\multicolumn{2}{|c|}{$\begin{array}{c}\text { Кількість хворих } \\
\text { із стабільним } \\
\text { перебігом } \\
(\mathrm{n}=50)\end{array}$}} & \multirow{2}{*}{\multicolumn{2}{|c|}{\begin{tabular}{|c|} 
Кількість хворих із \\
погіршенням стану \\
та розвитком \\
ускладнень \\
$(\mathrm{n}=13)$ \\
\end{tabular}}} & \multirow{2}{*}{\multicolumn{2}{|c|}{ Чутливість }} & \multirow{2}{*}{\multicolumn{2}{|c|}{ Специфічність }} \\
\hline \multirow{2}{*}{$\begin{array}{c}\text { рівень тиску } \\
\text { (мм.рт.ст.) }\end{array}$} & \multicolumn{2}{|c|}{ кількість хворих } & & & & & & & & \\
\hline & $\begin{array}{c}1 \text { обсте- } \\
\text { ження }\end{array}$ & $\begin{array}{c}2 \text { обсте- } \\
\text { ження }\end{array}$ & $\begin{array}{c}1 \text { обсте- } \\
\text { ження }\end{array}$ & $\begin{array}{c}2 \text { обсте- } \\
\text { ження }\end{array}$ & \begin{tabular}{|c|}
1 обсте- \\
ження \\
\end{tabular} & $\begin{array}{c}2 \text { обсте- } \\
\text { ження }\end{array}$ & $\begin{array}{c}1 \text { обсте- } \\
\text { ження }\end{array}$ & $\begin{array}{c}2 \text { обсте- } \\
\text { ження } \\
\end{array}$ & $\begin{array}{c}1 \text { обсте- } \\
\text { ження }\end{array}$ & $\begin{array}{c}2 \text { обсте- } \\
\text { ження } \\
\end{array}$ \\
\hline 1 & 2 & 3 & 4 & 5 & \begin{tabular}{|l|}
6 \\
\end{tabular} & 7 & 8 & $\begin{array}{l}9 \\
\end{array}$ & 10 & 11 \\
\hline$\geq 110(+)$ & 63 & 63 & 50 & 50 & 13 & 13 & \multirow[t]{2}{*}{1,00} & \multirow[t]{2}{*}{1,00} & \multirow[t]{2}{*}{0,00} & \multirow[t]{2}{*}{0,00} \\
\hline$<110(-)$ & 0 & 0 & 0 & 0 & 0 & 0 & & & & \\
\hline$\geq 120$ & 63 & 61 & 50 & 48 & 13 & 13 & \multirow[t]{2}{*}{1,00} & \multirow[t]{2}{*}{0,96} & \multirow[t]{2}{*}{0,00} & \multirow[t]{2}{*}{0,00} \\
\hline$<120$ & 0 & 2 & 0 & 2 & 0 & 0 & & & & \\
\hline$\geq 130$ & 63 & 59 & 50 & 47 & 13 & 12 & \multirow[t]{2}{*}{1,00} & \multirow[t]{2}{*}{0,94} & \multirow[t]{2}{*}{0,00} & \multirow[t]{2}{*}{0,08} \\
\hline$<130$ & 0 & 4 & 0 & 3 & 0 & 1 & & & & \\
\hline$\geq 140$ & 58 & 44 & 46 & 36 & 12 & 8 & \multirow[t]{2}{*}{0,92} & \multirow[t]{2}{*}{0,72} & \multirow[t]{2}{*}{0,08} & \multirow[t]{2}{*}{0,38} \\
\hline$<140$ & 5 & 19 & 4 & 14 & 1 & 5 & & & & \\
\hline$\geq 150$ & 42 & 30 & 35 & 23 & 7 & 7 & \multirow[t]{2}{*}{0,70} & \multirow[t]{2}{*}{0,46} & \multirow[t]{2}{*}{0,46} & \multirow[t]{2}{*}{0,46} \\
\hline$<150$ & 21 & 33 & 15 & 27 & 6 & 6 & & & & \\
\hline$\geq 160$ & 27 & 21 & 22 & 15 & 5 & 6 & \multirow[t]{2}{*}{0,44} & \multirow[t]{2}{*}{0,30} & \multirow[t]{2}{*}{0,62} & \multirow[t]{2}{*}{0,54} \\
\hline$<160$ & 36 & 42 & 28 & 35 & 8 & 7 & & & & \\
\hline
\end{tabular}


Продовження табл. 3

\begin{tabular}{|c|c|c|c|c|c|c|c|c|c|c|}
\hline 1 & 2 & 3 & 4 & 5 & 6 & 7 & 8 & 9 & 10 & 11 \\
\hline$\geq 170$ & 9 & 5 & 8 & 3 & 1 & 2 & \multirow[t]{2}{*}{0,16} & \multirow[t]{2}{*}{0,06} & \multirow[t]{2}{*}{0,92} & \multirow[t]{2}{*}{0,85} \\
\hline$<170$ & 54 & 58 & 42 & 47 & 12 & 11 & & & & \\
\hline$\geq 180$ & 8 & 2 & 7 & 1 & 1 & 1 & \multirow[t]{2}{*}{0,14} & \multirow[t]{2}{*}{0,02} & \multirow[t]{2}{*}{0,92} & \multirow[t]{2}{*}{0,92} \\
\hline$<180$ & 55 & 61 & 43 & 49 & 12 & 12 & & & & \\
\hline$\geq 190$ & 4 & 0 & 4 & 0 & 0 & 0 & \multirow[t]{2}{*}{0,08} & \multirow[t]{2}{*}{0,00} & \multirow[t]{2}{*}{1,00} & \multirow[t]{2}{*}{1,00} \\
\hline$<190$ & 59 & 63 & 46 & 50 & 13 & 13 & & & & \\
\hline$\geq 200$ & 2 & 0 & 2 & 0 & 0 & 0 & \multirow[t]{2}{*}{0,04} & \multirow[t]{2}{*}{0,00} & \multirow[t]{2}{*}{1,00} & \multirow[t]{2}{*}{1,00} \\
\hline$<200$ & 61 & 63 & 48 & 50 & 13 & 13 & & & & \\
\hline$\geq 210$ & 1 & 0 & 1 & 0 & 0 & 0 & \multirow[t]{2}{*}{0,02} & \multirow[t]{2}{*}{0,00} & \multirow[t]{2}{*}{1,00} & \multirow[t]{2}{*}{1,00} \\
\hline$<210$ & 62 & 63 & 59 & 50 & 13 & 13 & & & & \\
\hline$\geq 220$ & 1 & 0 & 1 & 0 & 0 & 0 & \multirow[t]{2}{*}{0,02} & \multirow[t]{2}{*}{0,00} & \multirow[t]{2}{*}{1,00} & \multirow[t]{2}{*}{1,00} \\
\hline$<220$ & 62 & 63 & 59 & 50 & 13 & 13 & & & & \\
\hline$\geq 230$ & 1 & 0 & 1 & 0 & 0 & 0 & \multirow[t]{2}{*}{0,02} & \multirow[t]{2}{*}{0,00} & \multirow[t]{2}{*}{1,00} & \multirow[t]{2}{*}{1,00} \\
\hline$<230$ & 62 & 63 & 59 & 50 & 13 & 13 & & & & \\
\hline
\end{tabular}

Порівняльний аналіз виявив переважання показників чутливості за результатами визначення показників верхнього артеріального тску при обстеженні до призначеного лікування, порівняно із обстеженням в процесі лікування, як маркерів включення до груп ризику розвитку ускладнень пацієнтів з гіпертензією на переважній більшості рівнів. Лише на 1 рівні показники чутливості не різнилися при першому та другому обстеженнях.
Показники специфічності на більшості рівнів $(1,2,5,8$ 13 рівні) не різнилися за результатами першого та другого обстежень. На 3 та 4 рівнях більш специфічним було друге, а на 6 і 7 - перше обстеження.

3 метою набору масивів даних для побудови ЯОСкривих визначено показники TPR (чутливість) та FPR (1 -специфічність) на кожному рівні артеріального тиску (табл. 4).

Таблиця 4. Показники ТРЯ (чутливості) та БРЯ (1-специфічності) за рівнями верхнього артеріального тиску при першому та другому обстеженнях хворих з гіпертензією

\begin{tabular}{c|c|c|c|c|c}
\hline \multirow{2}{*}{$\begin{array}{c}\text { № } \\
\text { за/п }\end{array}$} & $\begin{array}{c}\text { Рівень верхнього } \\
\text { артеріального тиску } \\
\end{array}$ & \multicolumn{2}{|c|}{ 1 обстеження } & \multicolumn{2}{|c}{ 2 обстеження } \\
\cline { 3 - 6 } & чм рт. ст.) & чутливість & 1-специфічність & чутливість & 1-специфічність \\
\hline 1 & 110 & 1,00 & 1,00 & 1,00 & 1,00 \\
\hline 2 & 120 & 1,00 & 1,00 & 0,96 & 1,00 \\
\hline 3 & 130 & 1,00 & 1,00 & 0,94 & 0,92 \\
\hline 4 & 140 & 0,92 & 0,92 & 0,72 & 0,62 \\
\hline 5 & 150 & 0,70 & 0,54 & 0,46 & 0,54 \\
\hline 6 & 160 & 0,44 & 0,38 & 0,30 & 0,46 \\
\hline 7 & 170 & 0,16 & 0,08 & 0,06 & 0,15 \\
\hline 8 & 180 & 0,14 & 0,08 & 0,02 & 0,08 \\
\hline 9 & 190 & 0,08 & 0,00 & 0,00 & 0,00 \\
\hline 10 & 200 & 0,04 & 0,00 & 0,00 & 0,00 \\
\hline 11 & 210 & 0,02 & 0,00 & 0,00 & 0,00 \\
\hline 12 & 220 & 0,02 & 0,00 & 0,00 & 0,00 \\
\hline 13 & 230 & 0,02 & 0,00 & 0,00 & 0,00 \\
\hline
\end{tabular}

ЯОС-аналіз результатів дослідження показників верхнього артеріального тиску у пацієнтів з гіпертензією в якості маркерів включення до групи ризику погіршення стану та розвитку ускладнень (рис. 2) показав більшу специфічність та чутливість показ- ників при першому обстеженні хворих. Площа, обмежена ROC-кривою і віссю частки помилкових позитивних класифікацій, була більшою при першому обстеженні, порівняно з другим, що показує на вищу якість даного класифікатора. 


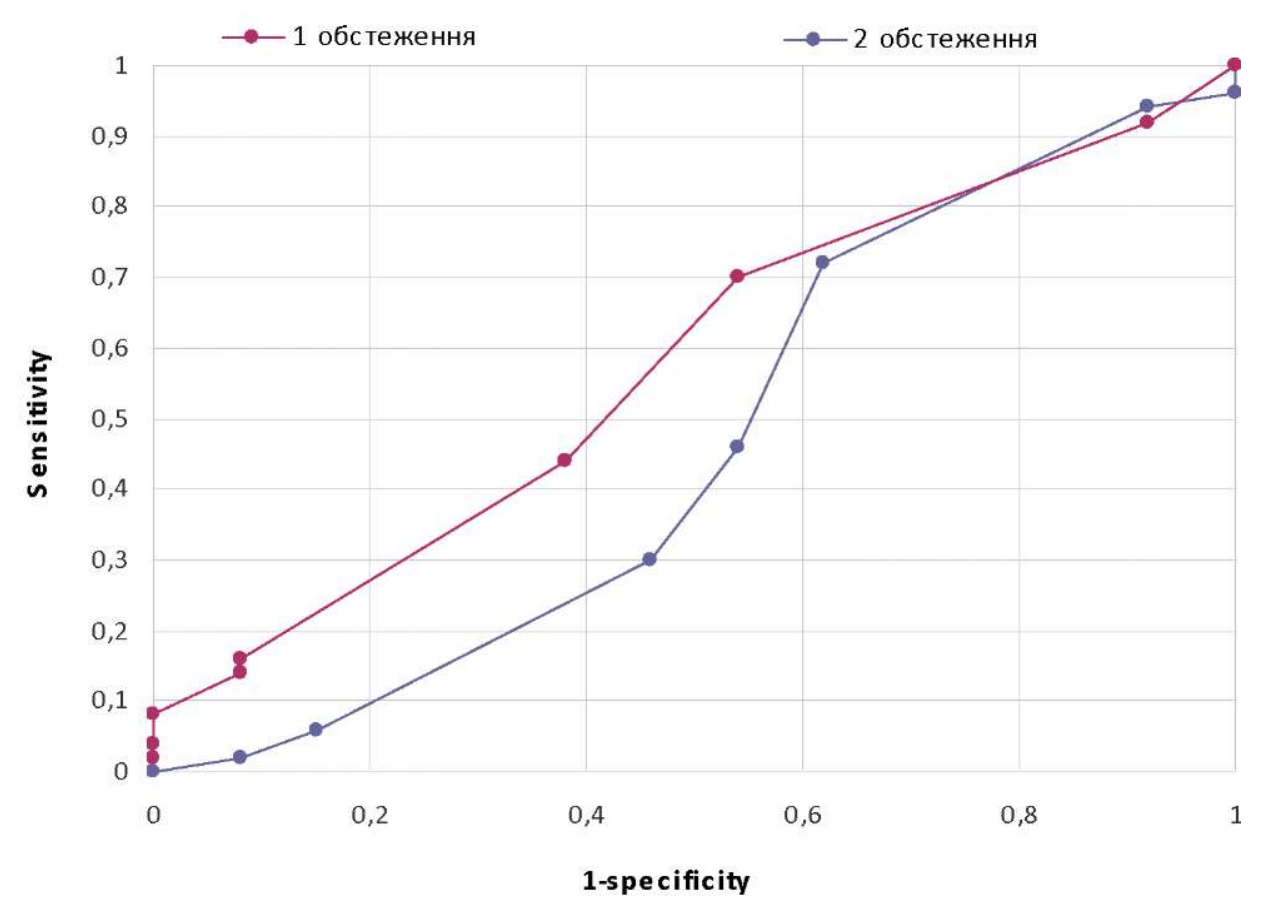

Puc. 2. ЯОС-аналіз результатів дослідження показників верхнього артеріального тиску при першому та повторному обстеженнях в якості маркерів включення до групи ризику погіршення стану та розвитку ускладнень у хворих з гіпертензією

Висновки. В роботі запропоновано метод оптимізації прогнозування пребігу захворювання на первинному рівні на основі комплексного аналізу гемодинамічних показників при першому (до призначеного лікування) та другому обстеженнях (в процесі лікування) хворих $з$ гіпертензією шляхом аналізу ROC-кривих.

3'ясовано, що показники рівня пульсу при обстеженні в процесі лікування є більш чутливими та специфічними в якості маркерів включення до групи ризику розвитку ускладнень та погіршення стану при гіпертензії, порівняно з первинним обстеженням. Площа, обмежена ROC-кривою і віссю частки помилкових позитивних класифікацій, була більшою при повторному обстеженні, що показує вищу якість даного класифікатора.

При прогнозуванні перебігу гіпертензії на основі

\section{Література}

1. Концепция информатизации здравоохранения в Украине / О. П. Минцер, Ю. В. Вороненко, Л. Ю. Бабинцева [и др.] // Медична інформатика та інженерія. - 2012. - № 3. C. 5-29.

2. Measuring patient-centered communication in patientphysician consultations: theoretical and practical issues / R. показників артеріального тиску в якості маркерів включення до групи ризику погіршення стану та розвитку ускладнень доцільніше використовувати дані обстеження до призначеного лікування. При цьому

ROC-аналіз результатів дослідження показників верхнього артеріального тиску показав більшу чутливість при первинному обстеженні хворих. Водночас на більшості рівнів артеріального тиску показники специфічності не різнилися за результатами першого та другого обстежень.

Перспективи подальших досліджень. Перспективним є запровадження методики ROC-аналізу для прогнозування перебігу захворювань на первинному рівні надання медичної допомоги з метою визначення чутливості та специфічності досліджуваних показників у різні періоди та за різними методиками, зважаючи на доступність та простоту у використанні.

M. Epstein, P. Franks, K. Fiscella [et al.] // Soc. Sci. Med. 2005. - Vol. 61. - P. 1516-1528.

3 Марценюк В. П. О программной среде проектирования интеллектуальных медицинских баз данных / В. П. Марценюк, Н. О. Кравец // Клиническая информатика и телемедицина - 2004. - №> 1. - С. 47-53. 
4. Інформаційна модель надання дистанційних медичних послуг населенню. Перше повідомлення / Г. Н. Востров, О. П. Мінцер, О. О. Павлов [та ін.]// Медична інформатика та інженерія. - 2010. - №> 3. - С. 37-47.

5. Ковальчук. Л. Я. Результати реалізації новітніх методик навчального процесу в Тернопільському державному медичному університеті імені І. Я. Горбачевського та плани на майбутнє / Л. Я. Ковальчук // Медична освіта. - 2012. - №> 2. - C. 11-17.
6 Signal detection theory and psychophysics. - New York, NY: John Wiley and Sons Inc., 1966.

7 Hanley J.A. Sampling variability of nonparametric estimates of the areas under receiver operating characteristic curves: an update / J. A. Hanley, K. O. Hajian-Tilaki // Academic Radiology. - 1997. - Vol. 4. - P. 49-58.

8. Hilgers R. A. Distribution-free confidence bounds for ROC curves / R. A. Hilgers // Methods of Information in Medicine. - 1991. - Vol. 30. - P. 96-101. 